\title{
Application of Genetic Algorithm to Calculation of Three-Suffix Margules Parameters in Ternary Extraction Ionic Liquid Systems
}

\author{
Gholamreza Vakili-Nezhaad* ${ }^{1}$, Mostafa Vatani ${ }^{2}$, Ashish M. Gujarathi ${ }^{1}$ \\ ${ }^{1}$ Department of Petroleum and Chemical Engineering, College of Engineering, Sultan Qaboos University, \\ P.O. Box: 33, Muscat 123, Oman \\ ${ }^{2}$ Department of Chemical Engineering, Amirkabir University of Technology, Tehran, Iran \\ Email: vakili@squ.edu.om
}

\begin{abstract}
The genetic algorithm is a powerful and effective tool and can be used to calculate fitting parameters of activity coefficient models in equilibrium systems. In previous work, the parameters of non-random two liquid, (NRTL) and two-suffix Margules models were calculated for 20 ternary extraction ionic liquid systems using the genetic algorithm method. This work is continuation of recent paper, in which the adjustable parameters of three-suffix Margules model have been calculated for considered ternary systems. For each system, the values of adjustable parameters along with the root mean square deviations (rmsd) are calculated. While the overall values of rmsd for 169 tie-lines in NRTL and two-suffix Margules models were 0.0039 and 0.0195 respectively, the overall rmsd value in three-suffix Margules model is 0.0091 and illustrate that also this model can be useful in prediction of phase behavior of liquid-liquid equilibrium in these systems.
\end{abstract}

Keywords: Liquid-liquid equilibrium; ionic liquid; genetic algorithm; three-suffix Margules model; parameter estimation.

\section{Introduction}

Parameter estimation in thermodynamic models has been of great interest in chemical engineering because of its complex nature, including nonlinearity, a flat objective function in the neighborhood of the global optimum, a badly scaled model, and non-differential term(s) in the equations. Parameter estimation in a (thermodynamic) model refers to determining the values of model parameters that best fit the model predictions to the given experimental data. Mathematically, it is formulated as the minimization of a suitable objective function subject to constraints arising from the model equations. For many thermodynamic models, the objective function and constraints are multimodal (non-convex). Hence, it is necessary to estimate the model parameters by using a global optimization method because traditional gradient-based optimization methods often provide a local solution only [1].

Stochastic global optimization techniques have been found to be powerful tools in many engineering applications. Genetic Algorithm, GA [2], Simulated Annealing, SA [3] and Differential Evolution, DE [4] are examples of some popular evolutionary algorithms based on the global optimization methods. Among these algorithms, in this work, the GA is introduced as an effective tool to solve the adjustable parameters of three-suffix Margules model in ternary extraction systems.

Recently, Singh et al. [5] utilized GA to estimate the binary interaction parameters for NRTL and UNIQUAC models in multi-component LLE systems and demonstrated that their performance was better than inside variance estimation method (IVEM) and the techniques applied in ASPEN and DECHEMA. Sahoo et al. [6,7] calculated the interaction parameters for NRTL and UNIQUAC models in ternary, quaternary and quinary LLE systems based on GA and showed that the results obtained using GA were better than other techniques in literature. Rashtchian et al. [8] studied the phase behavior of multi-component and multiphase systems based on GA and calculated the binary interaction parameters of Wilson, NRTL and the UNIQUAC models for a number of systems, and compared the binary interaction parameters for these models in VLE, VLLE and LLE systems with those reported in the literature. The results of this comparison showed very good predictions. Alvarez et al. [9] mentioned that stochastic optimization techniques had often been found to be as powerful and effective tool as deterministic methods in many engineering applications and used GA for parameter estimation in Wilson model for VLE systems.

In recent years, Ionic Liquids (ILs) have received increasing attention due to their potential technological applications. The ILs, as green solvents, have unique properties such as negligible vapor pressure, large temperature liquids range, high thermal stability, high ionic conductivity, large electrochemical window, and ability to solvate compounds of widely varying polarity. Nowadays, they are known as green solvents for future applications [10]. Over the past few years, research about ILs has been increased due to their unique specifications. Although an increasing amount of experimental phase equilibrium data of ternary extraction mixtures containing ILs is becoming available, it is important to be able to predict the phase equilibrium in such mixtures.

In previous work [11], based on the GA method, the well-known NRTL and two-suffix Margules models were used for correlation of 20 ternary extraction systems containing ILs and demonstrated that these models were able to well predict phase behavior in the mentioned systems. Beside these models, here are shown that also the three-suffix Margules model can be used for correlation of 
these systems. The values of the parameters for this model along with deviation between experimental and calculated mole fractions (rmsd) are calculated. The results, in terms of rmsd for this model are very satisfactory, with the overall values of 0.0091 for 169 tie-lines.

In a recent work we introduced this method for other systems and calculated the parameters of NRTL, NRTL1 and NRTL2 models [12]. The results, in terms of rmsd for NRTL, NRTL1, and NRTL2 models were satisfactory and the rmsd results for these models show that NRTL1 can predict the LLE calculations with more accuracy than the original NRTL and NRTL2 activity coefficient models.

The full names and abbreviations for the ILs used in ternary extraction systems are presented in Table 1.

Table 1. Abbreviation and full name of ionic liquids used in this work.

\begin{tabular}{|c|c|}
\hline Abbreviation & Full name of ionic liquid \\
\hline [mebupy] $\left[\mathrm{BF}_{4}\right]$ & 4-methyl-N-butylpyridinium tetrafluoroborate \\
\hline [3-mebupy][DCA] & 3-methyl-N-butyl pyridinium dicyanamide \\
\hline$[\mathrm{emim}]\left[\mathrm{ESO}_{4}\right]$ & 1-ethyl-3-methylimidazolium ethylsulfate \\
\hline$[\mathrm{bmim}]\left[\mathrm{MSO}_{4}\right]$ & 1-butyl-3-methylimidazolium methylsulfate \\
\hline$[\mathrm{bmim}]\left[\mathrm{BF}_{4}\right]$ & 1-butyl-3-methylimidazolium tetrafluoroborate \\
\hline$[\mathrm{bmim}]\left[\mathrm{NTf}_{2}\right]$ & $\begin{array}{l}\text { 1-butyl-3-methylimidazolium } \\
\text { bis\{trifluoromethylsulfonyl\}imide }\end{array}$ \\
\hline$[\mathrm{bmim}]\left[\mathrm{PF}_{6}\right]$ & 1-butyl-3-methylimidazolium hexafluorophosphate \\
\hline [omim $][\mathrm{CL}]$ & 1-octyl-3-methylimidazolium chloride \\
\hline$[\mathrm{hmim}]\left[\mathrm{BF}_{4}\right]$ & 1-hexyl-3-methylimidazolium tetrafluoroborate \\
\hline$[\mathrm{pmim}]\left[\mathrm{PF}_{6}\right]$ & 1-propyl-3-methylimidazolium hexafluorophosphate \\
\hline Ammoeng 102 & tetraalkyl ammonium sulfate \\
\hline$[\mathrm{bmim}][\mathrm{SCN}]$ & 1-butyl-3-methylimidazolium thiocyanate \\
\hline$[\mathrm{bpy}]\left[\mathrm{BF}_{4}\right]$ & N-butylpyridinium tetrafluoroborate \\
\hline$[\mathrm{EtMe}]\left[\operatorname{ImI}_{3}\right]$ & 1-ethyl-3-methylimidazolium triiodide \\
\hline$[\mathrm{bmim}][\mathrm{DCA}]$ & 1-butyl-3-methylimidazolium dicyanamide \\
\hline$[\mathrm{hmim}][\mathrm{TCB}]$ & 1-hexyl-3-methylimidazolium tetracyanoborate \\
\hline$[\mathrm{bmim}][\mathrm{TCB}]$ & 1-butyl-3-methylimidazolium tetracyanoborate \\
\hline$[\mathrm{omim}]\left[\mathrm{PF}_{6}\right]$ & 1-octyl-3-methylimidazolium hexafluorophosphate \\
\hline $\mathrm{C}_{2} \mathrm{NTf}_{2}$ & $\begin{array}{l}\text { ethyl(2-hydroxyethyl)dimethylammonium } \\
\text { bis }\{\text { (trifluomethyl)sulfonyl }\} \text { imide }\end{array}$ \\
\hline$[\mathrm{dmim}][\mathrm{MP}]$ & 1,3-dimethylimidazolium methylphosphonate \\
\hline
\end{tabular}

\section{Genetic Algorithm}

In recent years, genetic algorithm has been found to be a reliable algorithm for the complex engineering calculations. GA is based on the natural selection and the process that drives biological evolution. Those optimization problems that are not well suited for standard optimization algorithms, including problems in which the objective function is discontinuous, non-differentiable stochastic or highly nonlinear can be solved by the GA. GA differs from a derivative-based optimization algorithm in two main ways. Firstly, the derivative-based algorithm using only one single point in each iteration, while the GA explores the search space using multiple points. Secondly, the derivative-based algorithm generates new point by a deterministic computation, while the GA creates new population by a probabilistic computation

For the standard optimization algorithm, the fitness function is known as the objective function. The algorithm begins by creating random initial populations and modifies a population of individual solutions between the values of the lower and upper bounds of variables successively. The population size determines the size of the population at each generation. Increasing the population size enables the GA to search more points and thereby obtaining better results. At each step, the GA selects individuals from the current population stochastically to be the parents of the children for the next generation based on genetic operators including selection, crossover and mutation by exploring all regions of the search space. The procedure of the GA is summarized in Figure 1. In the first step, an initial population is generated. Each individual is evaluated for fitness in the next step. The best individuals are chosen from the selection step. Individuals with high probability receive more probability to produce offspring. The offspring are then generated by combination of these selected individuals using crossover step. In mutation step, random changes are applied to some individuals. The purpose of mutation operator is to prevent GA from converging to a local minimum and introducing new possible solutions into the population [13]. The algorithm continues to find the minimum of the fitness function and evaluated until termination criteria are reached.

A more complete discussion of the GA, including extension and related topics, can be found in [14].

\section{Liquid-Liquid Equilibrium Modeling}

The thermodynamic equilibrium condition between two liquid phases, i.e. the aliphatic rich phase $I$ and the IL rich phase $I I$, in terms of the molar fractions $x_{i}$ and activity coefficients $\gamma_{i}$, can be expressed in the following form:

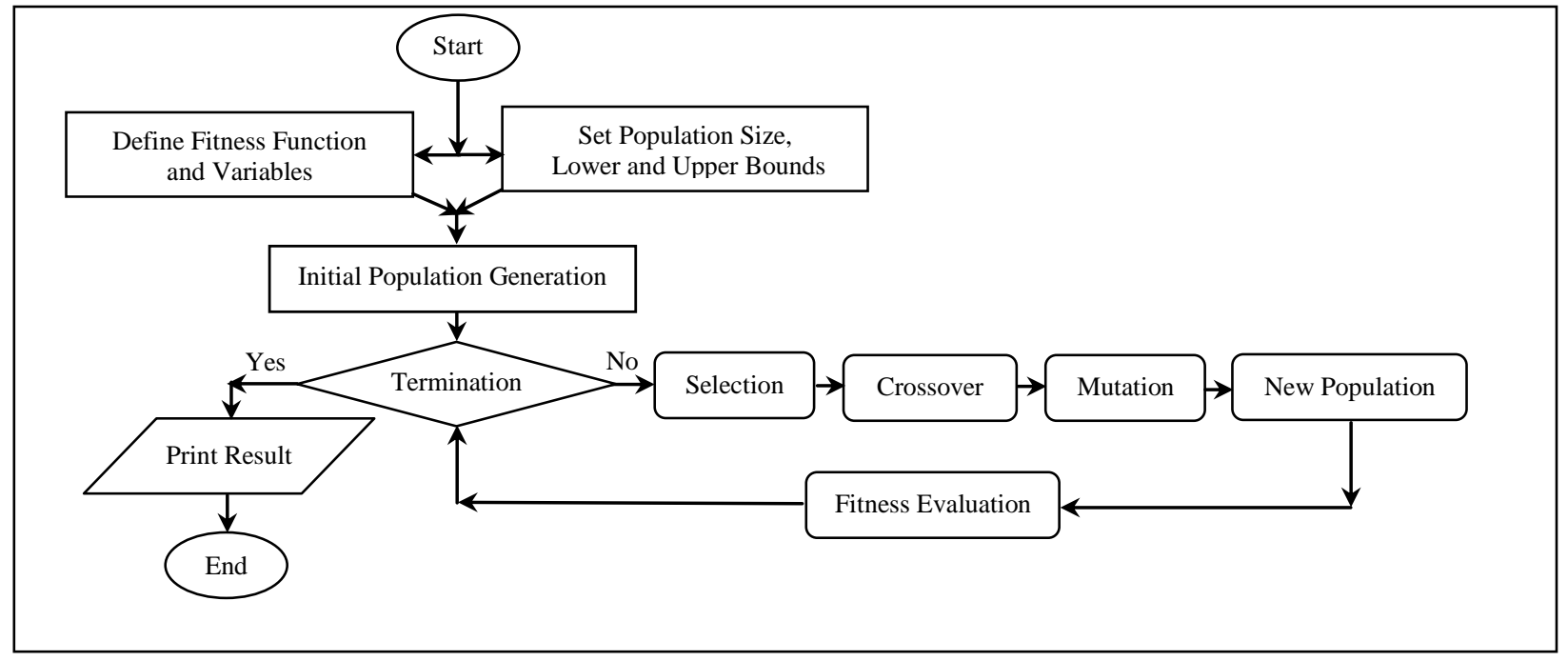

Figure 1. The flowchart of genetic algorithm. 
$\left(x_{i} \gamma_{i}\right)^{\mathrm{I}}=\left(x_{i} \gamma_{i}\right)^{\Pi}$

The molar component balances lead to the following equation:

$Z_{i}=x_{i}^{\mathrm{I}} L+x_{i}^{\Pi}(1-L)$

where $Z_{i}$ denotes the overall, or make up molar fraction, $x_{i}$ is the mole fraction of liquid phase, and $L$ the molar split ratio, i.e. 1 mole of make-up mixture splits into $L$ mole of aliphatic rich phase and $(1-L)$ mole IL rich phase.

The distribution ratio of component $i$, is given by:

$K_{i}=x_{i}^{\mathrm{I}} / x_{i}^{\mathrm{II}}$

Combining Eq. (3) with Eq. (2) with the fact that the molar fractions sum to unity in each phase, gives a Rachford-Rice type of equation [15]:

$\sum_{i} \frac{Z_{i}\left(1-K_{i}\right)}{1+L\left(K_{i}-1\right)}=0$

Combining Eq. (3) with Eq. (1) gives $K_{i}=\gamma_{i}^{\mathrm{II}} / \gamma_{i}^{\mathrm{I}}$, where $\gamma_{i}$ can be calculated from a proper activity coefficient models using an appropriate set of adjustable parameters.

\section{Three-Suffix Margules Model}

The three-suffix Margules model [16] was used to correlate experimental LLE data assuming that the components 1, 2, and 3 are approximately the same size. The activity coefficient for component 1 is given by Eq. (5)

$$
\begin{aligned}
& \ln \gamma_{1}=A_{12} x_{2}^{2}\left(1-2 x_{1}\right)+2 A_{21} x_{1} x_{2}\left(1-x_{1}\right)+A_{13} x_{3}^{2}\left(1-2 x_{1}\right) \\
& +2 A_{31} x_{1} x_{3}\left(1-x_{1}\right)-2 A_{23} x_{2} x_{3}^{2}-2 A_{32} x_{2}^{2} x_{3} \\
& +\left[\frac{1}{2}\left(A_{12}+A_{21}+A_{13}+A_{23}+A_{32}\right)-Q\right]\left(x_{2} x_{3}-2 x_{1} x_{2} x_{3}\right)
\end{aligned}
$$

where $A_{12}, A_{21}, A_{13}, A_{31}, A_{23}, A_{32}$ and $Q$ are adjustable parameters which are calculated by regression based on liquid-liquid equilibrium calculations for ternary systems used in this work. Expression for $\gamma_{2}$ and $\gamma_{3}$ can be obtained from (5) by a change of all subscripts on the right hand side. For $2 \gamma_{2}$ replace 1 with 2 , replace 2 with 3 and 3 with 1 ; and for $\gamma_{3}$ replace 1 with 3 , replace 2 with 1 and 3 with 2 .

\section{Parameter Estimation}

Estimation of the parameters was performed by the MATLAB code 7.8.0 (R2009a) based on the liquid-liquid flash calculation algorithm. In general, parameter estimation is considered as a minimization of a proper objective function. The objective function, $F_{o b j}$ [17] which minimizes the deviation between experimental and calculated mole fractions of the components can be expressed by:

$$
F_{o b j .}=\left[\sum_{i} \sum_{j} \sum_{k}\left(x_{i j k}^{\mathrm{exp}}-x_{i j k}^{c a l}\right)^{2}\right]
$$

The comparisons between experimental and calculated data can be made through root mean square deviations (rmsd) between experimental and calculated composition of each component in both phases. The rmsd is given by:

$r m s d=\left[\sum_{i} \sum_{j} \sum_{k}\left(x_{i j k}^{\exp }-x_{i j k}^{c a l}\right)^{2} / 6 M\right]^{1 / 2}$

where, $x$ is the mole fraction; the subscripts $i, j$ and $k$ provide a designation for the component, phase, and tie lines, respectively and the value $M$ designates the number of tie lines.

\section{Results and Discussion}

The parameters of three-suffix Margules model are calculated for 20 ternary extraction systems containing ILs. These systems are the same as systems used in previous work and are presented in Table 2. To calculate of adjustable parameters of this model, the stochastic global

\begin{tabular}{|c|c|c|c|c|}
\hline Sys. No. & Name of ternary systems & $T(\mathbf{K})$ & Tie-line & Ref. \\
\hline 1 & Propylbenzene $(1)+$ hexadecane $(2)+[$ mebupy $]\left[\mathrm{BF}_{4}\right](3)$ & 313.00 & 10 & {$[18]$} \\
\hline 2 & Benzene $(1)+$ hexane(2) + [3-mebupy][DCA] $(3)$ & 303.15 & 11 & [19] \\
\hline 3 & Benzene $(1)+$ hexane $(2)+[\mathrm{emim}]\left[\mathrm{ESO}_{4}\right](3)$ & 313.20 & 08 & {$[20]$} \\
\hline 4 & Benzene $(1)+$ hexane $(2)+[$ bmim $]\left[\mathrm{MSO}_{4}\right](3)$ & 328.20 & 08 & {$[21]$} \\
\hline 5 & Benzene $(1)+$ heptane $(2)+[\mathrm{bmim}]\left[\mathrm{BF}_{4}\right](3)$ & 298.15 & 08 & [17] \\
\hline 6 & $\operatorname{Benzene}(1)+\operatorname{octane}(2)+[\mathrm{bmim}]\left[\mathrm{NTf}_{2}\right](3)$ & 298.15 & 13 & {$[22]$} \\
\hline 7 & Benzene $(1)+$ undecane $(2)+\left[b_{m i m}\right]\left[\mathrm{PF}_{6}\right](3)$ & 298.15 & 05 & {$[23]$} \\
\hline 8 & Benzene $(1)+$ dodecane $(2)+[$ omim $][C L](3)$ & 298.20 & 04 & {$[24]$} \\
\hline 9 & Benzene $(1)+$ hexadecane $(2)+[\mathrm{hmim}]\left[\mathrm{BF}_{4}\right](3)$ & 298.20 & 09 & {$[25]$} \\
\hline 10 & Benzene $(1)+$ cyclohexane $(2)+[$ pmim $]\left[\mathrm{PF}_{6}\right](3)$ & 298.15 & 08 & [26] \\
\hline 11 & Toluene(1) + heptane(2) + Ammoeng102(3) & 298.15 & 08 & {$[27]$} \\
\hline 12 & Toluene $(1)+$ heptane $(2)+[$ bmim $][\mathrm{SCN}](3)$ & 303.15 & 07 & [28] \\
\hline 13 & Toluene $(1)+$ heptane $(2)+[b p y]\left[\mathrm{BF}_{4}\right](3)$ & 313.20 & 08 & [29] \\
\hline 14 & Toluene(1) + heptane $(2)+[\mathrm{EtMe}]\left[\operatorname{ImI}_{3}\right](3)$ & 318.15 & 14 & {$[30]$} \\
\hline 15 & Toluene $(1)+$ heptane $(2)+[$ bmim $][D C A](3)$ & 328.15 & 07 & [28] \\
\hline 16 & Toluene $(1)+$ methylcyclohexane $(2)+[$ hmim $][\mathrm{TCB}](3)$ & 293.15 & 09 & [31] \\
\hline 17 & Toluene $(1)+$ methylcyclohexane $(2)+[$ bmim $][\mathrm{TCB}](3)$ & 313.15 & 09 & [31] \\
\hline 18 & $\mathrm{~m}-\mathrm{Xylene}(1)+$ nonane $(2)+[\mathrm{omim}]\left[\mathrm{PF}_{6}\right](3)$ & 298.15 & 04 & {$[32]$} \\
\hline 19 & m-Xylene $(1)+$ hexane $(2)+\left[\mathrm{C}_{2} \mathrm{NTf}_{2}\right](3)$ & 298.15 & 10 & [33] \\
\hline 20 & Thiophene $(1)+$ heptane $(2)+[\operatorname{dmim}][\mathrm{MP}](3)$ & 298.15 & 09 & {$[17]$} \\
\hline Overall & & & 169 & \\
\hline
\end{tabular}
optimization method (GA) applied based on the liquid-liquid equilibrium calculation.

Table 2. List of Ternary Ionic Liquid Systems. 


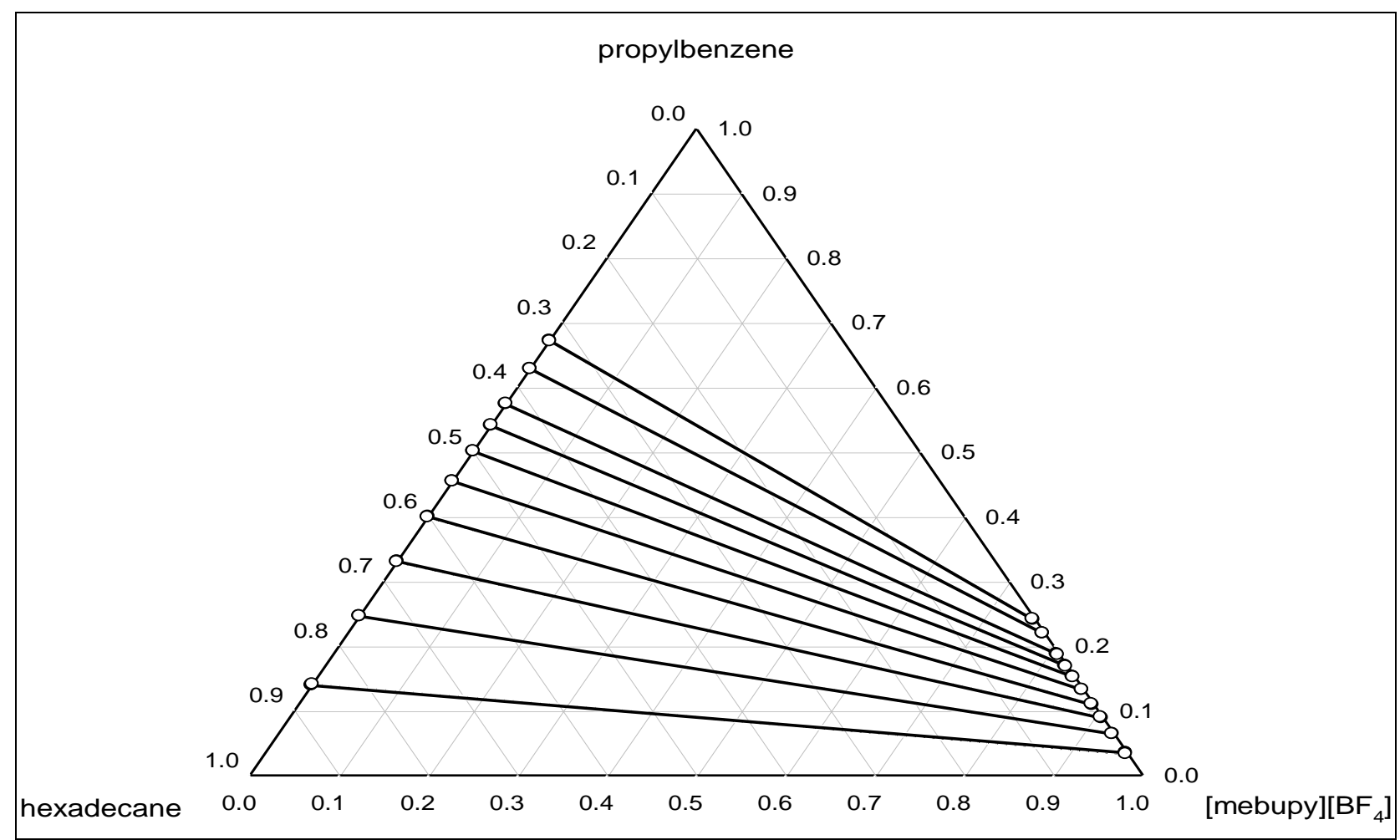

Figure 2. Tie-lines for system No. 1, solid lines and full points: experimental tie-lines; dashed lines and empty points: predicted tie-lines with three-suffix margules model.

In this method, each new generation decreases the objective function and it is seen that the $200^{\text {th }}$ generation provides the minimum value of objective function for threesuffix Margules model. GA uses random number generators algorithm which produces almost the same results at each runs. In order to obtain the lowest objective function, approximately 10 runs with random initial values of population, different operators and different lower and upper bounds for variable are tested, resulted in different values of the objective function and rmsd and the lowest rmsd along with the corresponding parameters are selected as the final results.

Table 3. The Calculated Parameters of Three-Suffix Margules Model for Ternary Systems Listed in Table 2.

\begin{tabular}{llllllll}
\hline $\begin{array}{l}\text { Sys. } \\
\text { No. }\end{array}$ & $\mathbf{A}_{\mathbf{1 2}}$ & $\mathbf{A}_{\mathbf{2 1}}$ & $\mathbf{A}_{\mathbf{1 3}}$ & $\mathbf{A}_{\mathbf{3 1}}$ & $\mathbf{A}_{\mathbf{2 3}}$ & $\mathbf{A}_{\mathbf{3 2}}$ & $\mathbf{Q}$ \\
\hline 1 & 1.482 & 2.988 & 3.178 & 1.627 & 5.650 & 39.020 & 8.669 \\
2 & -0.297 & 1.554 & -1.186 & 2.131 & 2.463 & 28.182 & 8.201 \\
3 & 2.128 & 1.958 & 2.631 & 1.587 & 4.386 & 26.626 & 3.302 \\
4 & 1.750 & 1.424 & 1.787 & 1.808 & 3.138 & 23.710 & 3.367 \\
5 & 0.277 & 1.620 & 0.339 & 2.138 & 4.185 & 18.045 & -4.999 \\
6 & 1.302 & 2.896 & 0.067 & 2.984 & 1.383 & 23.411 & 5.791 \\
7 & 8.832 & 2.863 & 1.240 & 1.955 & 2.881 & 12.820 & -4.999 \\
8 & 2.597 & 2.093 & 2.399 & 1.918 & 2.821 & 27.614 & 3.780 \\
9 & -2.772 & 1.318 & 0.599 & 2.598 & 1.903 & 32.462 & -4.988 \\
10 & 2.512 & 2.984 & 2.481 & 3.182 & 2.655 & 9.172 & -0.945 \\
11 & 1.215 & 1.628 & 2.267 & 3.073 & -1.463 & 17.424 & 9.100 \\
12 & -0.447 & -1.183 & -0.066 & 3.215 & 4.598 & 20.195 & 3.770 \\
13 & 2.235 & 3.458 & 3.383 & 1.624 & 3.834 & 38.000 & -4.997 \\
14 & 2.411 & 2.799 & 2.242 & 3.050 & 3.025 & 31.562 & 8.980 \\
15 & -0.710 & -1.206 & -0.663 & 2.896 & 2.804 & 37.090 & 9.093 \\
16 & 1.812 & 2.446 & 0.614 & 2.603 & 0.680 & 7.488 & -4.246 \\
17 & 0.710 & 2.043 & 0.281 & 2.393 & 0.740 & 11.202 & -1.651 \\
18 & 5.840 & 1.662 & -1.442 & 1.450 & -4.826 & 20.364 & -5.000 \\
19 & 0.660 & 1.200 & 1.989 & 2.357 & 2.378 & 33.343 & 8.792 \\
20 & 0.888 & 0.959 & 0.797 & 4.411 & 5.716 & 37.866 & -3.931 \\
\hline
\end{tabular}

The calculated parameters of three-suffix Margules model for all systems are listed in Table 3 and depended on the kind of each system. Table 4 shows the results of rmsd for NRTL, two and three-suffix Margules models for all systems using the GA method, and for NRTL model using other methods in literature.

Table 4. The Results of Rmsd Obtained Using the GA (This Work And Previous Work) and Other Methods in Literature.

\begin{tabular}{|c|c|c|c|c|}
\hline \multirow{2}{*}{ Sys. No. } & \multicolumn{2}{|c|}{ NRTL } & \multirow{2}{*}{$\begin{array}{l}\text { Two-Suffix } \\
\text { Margules } \\
\left(G A^{*}\right)\end{array}$} & \multirow{2}{*}{$\begin{array}{l}\text { Three-Suffix } \\
\text { Margules } \\
\text { (GA: this work) }\end{array}$} \\
\hline & Lit. & $G A^{*}$ & & \\
\hline 1 & 0.0021 & 0.0013 & 0.0019 & 0.0008 \\
\hline 2 & 0.0155 & 0.0038 & 0.0179 & 0.0089 \\
\hline 3 & 0.0029 & 0.0008 & 0.0040 & 0.0002 \\
\hline 4 & 0.005 & 0.0008 & 0.0078 & 0.0004 \\
\hline 5 & 0.0236 & 0.0039 & 0.0073 & 0.0058 \\
\hline 6 & 0.0041 & 0.0024 & 0.0212 & 0.0099 \\
\hline 7 & 0.0443 & 0.0031 & 0.0339 & 0.0102 \\
\hline 8 & 0.0020 & 0.0004 & 0.0088 & 0.0016 \\
\hline 9 & 0.0160 & 0.0059 & 0.0230 & 0.0123 \\
\hline 10 & 0.0065 & 0.0030 & 0.0220 & 0.0123 \\
\hline 11 & 0.0280 & 0.0062 & 0.0339 & 0.0099 \\
\hline 12 & 0.0050 & 0.0018 & 0.0193 & 0.0062 \\
\hline 13 & 0.0096 & 0.0038 & 0.0038 & 0.0029 \\
\hline 14 & 0.0145 & 0.0048 & 0.0184 & 0.0131 \\
\hline 15 & 0.0051 & 0.0027 & 0.0192 & 0.0065 \\
\hline 16 & 0.0157 & 0.0036 & 0.0292 & 0.0136 \\
\hline 17 & 0.0188 & 0.0060 & 0.0273 & 0.0134 \\
\hline 18 & 0.0359 & 0.0051 & 0.0318 & 0.0143 \\
\hline 19 & 0.0090 & 0.0028 & 0.0130 & 0.0070 \\
\hline 20 & 0.0108 & 0.0056 & 0.0035 & 0.0020 \\
\hline Overall & 0.0159 & 0.0039 & 0.0195 & 0.0091 \\
\hline
\end{tabular}
Ref. [11]

In previous work the overall rmsd values of NRTL model were 0.0039 and 0.0159 for 169 tie-lines using the GA method, and other methods in literature respectively, so 
this result confirmed that the GA produces more accurate results compared with the other techniques. The overall rmsd value for two-suffix Margules model was 0.0195. The overall value of 0.0091 for three-suffix Margules model shows that this model is better in comparison with the twosuffix Margules model. However, the NRTL model can be used as the best model in prediction of LLE systems containing ILs.

Although the NRTL model is the best model, but it is not the simplest model and it is introduced that two models (two and three suffix Margules models) are the simple models for prediction of these systems. Since the two and three suffix Margules model have 3 and 7 parameters respectively, it is clear that three suffix model can provides the behavior of the systems with better accuracy.

The comparisons between experimental and predicted tie-lines with three-suffix Margules model are shown in Figure 2 for the system No.1. In this figure, it is hard to discern the difference between the experimental and calculated values, so the figure confirmed the accuracy of this model with calculated parameters based on the GA method. Similar figures could be plotted for all the systems considered in this work.

\section{Conclusions}

The new approach based on the genetic algorithm is applied for fitting the parameters of three-suffix Margules model in 20 ternary extraction systems containing ionic liquids. These predictions are compared with the previously determined parameters of the NRTL and two-suffix Margules models. The overall rmsd values of NRTL model are 0.0039 and 0.0159 for 169 tie-lines based on the GA method, and other methods in literature, respectively. The overall rmsd values for 169 tie-lines in two- and three-suffix Margules models are 0.0195 and 0.0091 , respectively. Although, the three-suffix Margules model is better than the two-suffix model, the NRTL model can be used as the best model in prediction of LLE systems containing ILs. Genetic algorithm produces more accurate predictions compared with the traditional techniques and can be applied to obtain the parameters of other activity coefficient models using the proposed approach in this work.

\section{References}

[1] H. Zhang, G. P. Rangaiah, A. Bonilla-Petriciolet, Integrated differential evolution for global optimization and its performance for modeling vapor-liquid equilibrium data, Ind. Eng. Chem. Res., 50, 1004710061,2011

[2] J. H. Holland, Algoritmos geneticos, Investigacion. $Y$. Ciencia, 192, 38-45, 1992.

[3] S. Kirkpatrick, C. D. Gelatt, M. P. Vecchi, Optimization by simulated annealing, Science, 220, 671-680, 1983.

[4] K. V. Price, R. M. Storn, J. A. Lampinen, Differential Evolution a practical approach to global optimization, Germany: Springer-Verlag Berlin Heidelberg, 2005.

[5] M. K. Singh, T. Banerjee, A. Khanna, Genetic algorithm to estimate interaction parameters of multicomponent systems for liquid-liquid equilibria, Comput. Chem. Eng., 29, 1712-1719, 2005.

[6] R. K. Sahoo, T. Banerjee, S. A. Ahmad, A. Khanna, Improved binary parameters using GA for multicomponent aromatic extraction: NRTL model without and with closure equations, Fluid Phase Equilib., 239, $107-119,2006$
[7] R. K. Sahoo, T. Banerjee, A. Khanna, UNIQUAC interaction parameters with closure for imidazolium based ionic liquid systems using genetic algorithm, Can. J. Chem. Eng., 85, 833-853, 2007.

[8] D. Rashtchian, S. Ovaysi, V. Taghikhani, C. Ghotbi, Application of the genetic algorithm to calculate the interaction parameters for multiphase and multicomponent systems, Iran. J. Chem. Chem. Eng., 26, 89-102, 2007.

[9] V. H. Alvarez, R. Larico, Y. Ianos, M. Aznar, Parameter estimation for VLE calculation by global minimization: The genetic algorithm, Braz. J. Chem. Eng., 25, 409418, 2008

[10] F. Nami, F. Deyhimi, Prediction of activity coefficients at infinite dilution for organic solutes in ionic liquids by artificial neural network, J. Chem. Thermodyn., 43, 22-27, 2011.

[11] M. Vatani, M. Asghari, G. Vakili-Nezhaad, Application of genetic algorithm to the calculation of parameters for NRTL and Two-Suffix Margules models in ternary extraction ionic liquid systems, J. Ind. Eng. Chem., 18, 1715-1720, 2012.

[12] G. Vakili-Nezhaad, M. Vatani, M. Asghari, Calculation of the Binary Interaction and Nonrandomness Parameters of NRTL, NRTL1, and NRTL2 Models Using Genetic Algorithm for Ternary Ionic Liquid Systems, Chem. Eng. Comm., 200, 11021120, 2013.

[13] C. Preechakul, S. Kheawhom, Modified genetic algorithm with sampling techniques for chemical engineering optimization, J. Ind. Eng. Chem., 15, 110 118, 2009.

[14] Genetic Algorithm and Direct Search toolbox users guide, Copyright by the math works, Inc, 2004-2006.

[15] J. D. Seader, E. J. Henley, Separation process principles, $2^{\text {nd }} E d$. New York: John Wiley \& Sons, Inc, 2006.

[16] J. M. Prausnitz, R. N. Lichtenthaler, E. G. Azevedo, Molecular Thermodynamics of Fluid Phase Equilibria, $3^{\text {rd }}$ Ed. New York: Prentice-Hall, 1999.

[17] A. L. Revelli, F. Mutelet, J. N. Jaubert, Extraction of benzene or thiophene from n-heptane using ionic liquids. NMR and thermodynamic study, J. Phys. Chem. $B, 114,4600-4608,2010$.

[18] K. H. A. E. Alkhaldi, M. S. Al-Tuwaim, M. S. Fandary, A. S. Al-Jimaz, Separation of propylbenzene and n-alkanes from their mixtures using 4-methyl-Nbutylpyridinium tetrafluoroborate as an ionic solvent at several temperatures, Fluid Phase Equilib., 309, 102 107, 2011.

[19] A. R. Hansmeier, M. Jongmans, G. W. Meindersma, A. B. de Haan, LLE data for the ionic liquid 3-methyl$\mathrm{N}$-butyl pyridinium dicyanamide with several aromatic and aliphatic hydrocarbons, J. Chem. Thermodyn., 42, 484-490, 2010.

[20] J. García, A. Fernández, J. S. Torrecilla, M. Oliet, F. Rodríguez, Liquid-liquid equilibria for \{hexane + benzene +1 -ethyl-3-methylimidazolium ethylsulfate $\}$ at 
(298.2, 313.2 and 328.2) K, Fluid Phase Equilib., 282, 117-120, 2009.

[21] J. García, A. Fernández, J. Torrecilla, M. Oliet, F. Rodríguez, Ternary liquid-liquid equilibria measurement for hexane and benzene with the ionic liquid 1-butyl-3-methylimidazolium methylsulfate at $\mathrm{T}$ $=(298.2,313.2$, and 328.2) K, J. Chem. Eng. Data, 55, 258-261, 2010 .

[22] I. Domínguez, E. J. González, R. González, A. Domínguez, Extraction of benzene from aliphatic compounds using commercial ionic liquids as solvents: study of the liquid-liquid equilibrium at $\mathrm{T}=298.15 \mathrm{~K}$, J. Chem. Eng. Data, 56, 3376-3383, 2011.

[23] R. M. Maduro, M. Aznar, Liquid-liquid equilibrium of ternary systems 1-butyl-3-methylimidazolium hexafluorophosphate + aromatic + aliphatic, Fluid Phase Equilib., 265, 129-138, 2008.

[24] T. M. Letcher, N. Deenadayalu, Ternary liquid-liquid equilibria for mixtures of 1-methyl-3-octyl-imidazolium chloride + benzene + an alkane at $\mathrm{T}=298.2 \mathrm{~K}$ and 1 atm, J. Chem. Thermodyn., 35, 67-76, 2003.

[25] T. M. Letcher, P. Reddy, Ternary (liquid + liquid) equilibria for mixtures of 1-hexyl-3-methylimidazolium (tetrafluoroborate or hexafluorophosphate) + benzene + an alkane at $\mathrm{T}=298.2 \mathrm{~K}$ and $\mathrm{p}=0.1 \mathrm{MPa}, \mathrm{J}$. Chem. Thermodyn., 37, 415-421, 2005.

[26] T. Zhou, Z. Wang, L. Chen, Y. Ye, Z. Qi, H. Freund, K. Sundmacher, Evaluation of the ionic liquids 1-alkyl3-methylimidazolium hexafluorophosphate as a solvent for the extraction of benzene from cyclohexane: (Liquid + liquid) equilibria, J. Chem. Thermodyn., 48, 145-149, 2012.

[27] A. B. Pereiro, A. Rodriguez, Application of ionic liquid Ammoeng 102 for aromatic/aliphatic hydrocarbon separation, J. Chem. Thermodyn., 41, 951956, 2009.

[28] A. R. Hansmeier, M. Minoves Ruiz, G. W. Meindersma, A. B. de Haan, Liquid-liquid equilibria for the three ternary systems (3-methyl-N-butylpyridinium dicyanamide + toluene + heptane), (1-butyl-3methylimidazolium dicyanamide + toluene + heptane) and (1-butyl-3-methylimidazolium thiocyanate + toluene + heptane $)$ at $\mathrm{T}=(313.15$ and 348.15$) \mathrm{K}$ and $\mathrm{P}$ = 0.1 MPa, J. Chem. Eng. Data, 55, 708-713, 2010.

[29] J. García, S. García, J. Torrecilla, M. Oliet, F. Rodríguez, Liquid-liquid equilibria for the ternary systems heptane + toluene $+\mathrm{N}$-butylpyridinium tetrafluoroborate or $\quad \mathrm{N}$-hexylpyridinium tetrafluoroborate $\}$ at $\mathrm{T}=313.2 \mathrm{~K}, \mathrm{~J}$. Chem. Eng. Data, 55, 2862-2865, 2010.

[30] M. S. Selvan, M. D. McKinley, R. H. Dubois, J. L. Atwood, Liquid-liquid equilibria for toluene + heptane + 1-ethyl-3-methylimidazolium triiodide and toluene + heptane + 1-butyl-3-methylimidazolium triiodide, $J$. Chem. Eng. Data, 45, 841-845, 2000.

[31] J. P. Gutierrez, W. Meindersma, A. B. de Haan, Binary and ternary (liquid + liquid) equilibrium for \{methylcyclohexane (1) + toluene (2) + 1-hexyl-3methylimidazolium tetracyanoborate (3) /1-butyl-3methylimidazolium tetracyanoborate (3)\}, J. Chem. Thermodyn., 43, 1672-1677, 2011.

[32] R. M. Maduro, M. Aznar, Liquid-liquid equilibrium of ternary systems 1-octyl-3-methylimidazolium hexafluorophosphate + aromatic + aliphatic hydrocarbons, Fluid Phase Equilib., 296, 88-94, 2010.

[33] U. Dománska, A. Pobudkowska, M. Krolikowski, Separation of aromatic hydrocarbons from alkanes using ammonium ionic liquid C2NTf2 at T $=298.15 \mathrm{~K}$, Fluid Phase Equilib., 259, 173-179, 2007. 